\title{
Scenario for a patient at home in health and social care
}

This article was published in the following Dove Press journal:

Journal of Healthcare Leadership

3 October 2014

Number of times this article has been viewed

\author{
Monica Winge' \\ Eva Lindh-Waterworth ${ }^{2}$ \\ 'Department of Computer and \\ Systems Sciences, Stockholm \\ University, Stockholm, Sweden; \\ ${ }^{2}$ Department of Informatics, \\ Umeå University, Umeå, Sweden
}

Correspondence: Monica Winge Department of Computer and Systems Sciences, Stockholm University, SE II 4 I8, Stockholm, Sweden Tel +46707680080

Email winge@dsv.su.se
Abstract: This paper describes and discusses the situation for a typical patient with multiple illnesses and how his case would benefit from improved coordination, communication, and collaboration among all involved care providers. The paper is built around a patient case presented in a current scenario. The authors identified that for a single patient with several problems and diagnoses and the involvement of several care actors, the common issues concern lack of collaboration, lack of coordination, and awareness of what others have done to assess, plan, perform, and evaluate care. This presumably leads to a lack of care quality and a lack of effective use of care resources. The scenario and the findings are based on a patient-oriented perspective, on an analysis expressed in focus groups, and on interviews with key actors in health and social care. The paper also discusses the fact that an increasing number of patients are treated in their homes by a variety of organizations, and how this fact raises new and more intense demands on the various stakeholders forming the care staff to collaborate and coordinate care. We point to the need for managers in and between organizations to agree on the ways of collaborating at the operational level. Most importantly, by taking a basic set of issues as the starting point for reasoning, we derived a set of related problems and suggest solutions to deal with these. The literature currently lacks scenario descriptions that put the patient's situation into focus with respect to collaboration between health and social care. Finally, the paper presents a future case for collaboration including support by new e-services.

Keywords: multisectorial collaboration, coordination, communication, patient-centered care, home care, health and social care

\section{Introduction}

The areas of health and social care in Sweden, as well as in the rest of the world, are currently in a phase of great change. In Sweden today, there are 1.6 million people at an age $>65$ years, representing $18 \%$ of the population. The elderly population has increased both in number and in proportion, a tendency that will remain. At the end of the forecast period (2060), the estimated number of citizens of age $>65$ years is expected to be 2.7 million, or $25 \%$ of the population. If the retirement age remains at 65 , it means that around 2060 , one person in four would be retired. ${ }^{1}$

By 2030, the population in the USA will - compared to the case in 2014 include three times more people $>65$ years, five times more people $>85$ years and 20 times more people $>100$ years. $^{2}$ The aging of the population, ie, increase in average life expectancy, puts pressure on the affordability of health and social care services. According to Wood and Gray, ${ }^{3}$ this poses new and heavy demands on health and social care personnel to communicate, to coordinate, and to collaborate. 
Effective collaboration in health and social care is central to delivering high-quality practice and services.

However, communication difficulties between professions can inhibit care delivery. ${ }^{4,5}$ There will be a great need for coordination in the assessment of care needs, care planning, team building, and better use of care resources. ${ }^{6}$ We have to accept a future where we will have an increased number of patients with multiple diagnoses and the need for a variety of health care providers. One important change with subsequent challenges concerns the fact that an increasing number of patients are treated and taken care of in their own homes instead of in hospitals and nursing homes.

The aim of this paper is to illustrate the situation for a patient with multiple illnesses who is cared for by several care providers, and the needs this induces for coordination, communication and collaboration between all the care units, individuals, and professions involved.

A fictional, though typical, scenario is used as a communication tool to explain this complex care situation. The scenario was developed within the three national Swedish research and development projects, Sams, ${ }^{7}$ MobiSams, ${ }^{8}$ and Värdeskapande Vårdprocesser Project ${ }^{9}$ (VVP), where it was used also to explain this care situation, particularly for senior management, for example, on strategic and policy levels.

Later, we saw that, since the scenario was considered typical for this category of patients, one could also use it as an analytical tool to highlight concretely the type of improvements necessary. Hence, the paper also aims to suggest ways in which information and communication technology (ICT)-based solutions can be designed and can enable an improved coordinated and integrated patient-centered collaborative care. The paper also discusses a future situation, in which all involved are supported by new collaborative information services.

\section{Methods}

The patient scenario is based on knowledge acquired by interviewing all types of stakeholders involved and was developed by brainstorming in focus groups with the aim of identifying issues of collaboration among individuals, patients, relatives, care professions, and patient organizations. Experts in various fields of health and social care attended the focus groups. The patients and the relatives were interviewed (Table 1). The focus groups, therefore, set out to describe a typical such patient and put him in a scenario such that it would be possible to identify the communication and collaboration shortcomings that might turn up. Using the literature, seminars, and interviews also identified issues, problems, and needs.
Table I Summary table of completed focus groups and interviews

\begin{tabular}{lllll}
\hline $\begin{array}{l}\text { Completed } \\
\text { focus groups }\end{array}$ & $\begin{array}{l}\text { Focus } \\
\text { groups } \\
\text { (Sams) }\end{array}$ & $\begin{array}{l}\text { Focus } \\
\text { groups } \\
\text { (MobiSams) }\end{array}$ & $\begin{array}{l}\text { Interviews } \\
\text { (MobiSams) }\end{array}$ & $\begin{array}{l}\text { Interviews } \\
\text { (VVP) }\end{array}$ \\
\hline Patient board & - & - & 1 & 2 \\
Patient & - & - & 1 & 1 \\
organization & & & & \\
Patients & - & - & 1 & 2 \\
Relatives & - & - & 1 & 2 \\
Nurses & 3 & 3 & 2 & 3 \\
Doctors & 2 & 2 & 2 & 2 \\
Social care & 2 & 2 & 2 & 3 \\
staff & & & & \\
Paramedicine & 1 & 1 & 1 & 1 \\
Managers & 1 & 2 & 2 & 2 \\
Researcher & 1 & 6 & 2 & 3 \\
ICT- & 2 & 2 & 2 & 2 \\
developers & & & 17 & 23 \\
Total & $\mathbf{1 2}$ & $\mathbf{1 8}$ & $\mathbf{1 7}$ & \\
\hline
\end{tabular}

Abbreviations: VVP, Värdeskapande Vårdprocesser Project; ICT, information and communication technology.

Patients with multiple diagnoses and cared for by a multitude of care providers were identified as the most problematic. The scenario was developed in steps during 2005-2008 during approximately 15 meetings with the focus groups. It is based on a number of real patient cases with multiple illnesses and patients in palliative situations as described by the respondents. Interviewing patients, relatives, and professionals in health and social care complemented this information. The interview surveys have been performed with semistructured questions. ${ }^{10,11}$ The respondents (Table 1) have read the interview transcriptions when this has been possible. Altogether the work resulted in a list of problems of collaboration between health and social care, covering - for example - a lack of coordination, lack of clear regulation and responsibility for collaboration and coordination (who is doing what), and a general lack of common care processes and structured information.

Table 1 shows the number and types of respondents that participated in the focus groups and in the interviews. The authors acted as facilitators and are not included in the table. Information technology (IT) developers and researchers were not involved in the development of the scenario, but they were in discussions concerning development of information services.

The studies included a total of 70 different respondents. The focus groups also included two facilitators. The interviewees were always different from those involved in the focus groups.

The scenario has been tested, used, and verified in the following actions: 
- The scenario has been evaluated in a study as an inspiration in the ICT report, Koch et al, ${ }^{12}$ as a basis for creating an understanding of the problems around a complex health and care situation in the patient's home. The scenario provided a robust basis for the interviews with 15 key professionals from public and private health care organizations, the ICT industry, the Ministry of Social Affairs, the National Board of Health and Welfare, the Swedish Association of Local Authorities and Regions, and patient organizations. All of the respondents agreed that the scenario experiences were consistent with reality.

- The scenario was described and adapted for the screen in the Gustav video. ${ }^{13}$ The film was shown in two contexts, at conferences and seminars at a Vitalis Conference in Gothenburg, Sweden, in 2007, and in the MobiSams final project seminar in 2008 .

- A Gustav Theater was performed in front of about 100 people, including care professionals, patient organizations, and health care managers at the MobiSams final seminar 2008.

- Two care policy units for elderly care in Stockholm and Gothenburg evaluated the scenario in 2013. Their view was that the scenario fits well with the current situation.

\section{Background and related research}

The current world population by 2013 of 7.2 billion is projected to increase by almost 1 billion people within the next 12 years, reaching 8.1 billion in 2025 and then 9.6 billion in 2050, according to a United Nations report. ${ }^{14}$ This demographic change poses significant challenges to society and the economy. Most of the countries worldwide have a great need for improvement in the health care processes, collaboration, and better use of resources with large aging populations. ${ }^{14,15}$ The proportion of elderly people in society will increase. At the same time, the productive part of the population will be decreasing. This creates a tough challenge for the staffing of health and social care, as the average lifetime expectancy continues to rise. The care situation becomes even more complicated by the fact that many of the professionals involved belong to different organizational units, often with different owners - private, county councils, and municipalities. As a result, the distribution of responsibility may be unclear with sometimes more than one unit or individual care professional holding some - but not full - responsibility for the patient.

This type of problem is not new in Sweden. It has been discussed over at least the past 15 years, but it has - in the last years - gained momentum by triggering more interest in the media. Decentralization increases demands on the coordination of care actions and on patient influence (patient empowerment). What we henceforth can expect is that the patients/citizens (and their relatives) will be more active in their own care process, which places additional need for and demands on coordination and collaboration.

One of the reasons for the increased and increasing number of people in need of care is that health care has become much better at treating serious diagnoses. Hence, patients live with their diseases for a long time, requiring ever more care resources. ${ }^{16,17}$ Many professions and individuals may be involved, leading to increased demands for collaboration and coordination among care providers. The situation becomes even more complicated by the fact that many of the actors involved can belong to different care units, having different ownerships. These complex care situations involve care units in parallel and in asynchronous processes when implementing health care. This adds to the complexity as health and social care at home typically requires that many care parties with different specialties be involved, private as well as public ones. ${ }^{18-20}$ Not only health care is required but also social care with assistance for daily living. ${ }^{21,22}$ Furthermore, informal care parties, such as family members, friends, and neighbors, obtain a more prominent role for support and mediation. ${ }^{23}$ Collaboration and coordination between different organizations is a complex matter and may, for a single patient, involve a set of entangled care processes - each run by a separate care unit. ${ }^{24-26}$

Existing research has focused on a wide variety of aspects concerning collaboration within health care. Van Eyk and Baum $^{27}$ have studied what they define as interagency collaboration. To work smoothly, care actions in processes need to be coordinated. A broad definition of coordination is "the act of working together harmoniously" coordination theory by Malone and Crowston. ${ }^{28}$ One way of making this more precise is to note that processes are about common goals and that the process participants should respect dependencies that may exist between the care actions of processes. Thus, Malone and Crowston ${ }^{28}$ suggest the following definition of coordination: "the act of managing interdependencies between care actions performed to achieve a goal." Hudson $^{29}$ has studied joint commissions across the primary health care boundary in the UK. El Ansari et al ${ }^{30}$ have focused on the public health nurse's perspectives on collaborative partnerships in South Africa. They also investigated collaboration and partnership and the problems with measuring collaborative outcome. ${ }^{31}$ Lichtenstein et $\mathrm{al}^{32}$ have studied the effect 
that the status difference has on individual members in crossfunctional teams. It is also possible to find some examples in the field of mobile work and information processing. In the health care area, Ammenwerth et al $^{33}$ explore how mobile artifacts can be used for information processing in a hospital. Pascoe $^{34}$ describes how mobile artifacts increase the amount and speed of data being recorded in the field. According to Eng and Torpe ${ }^{35}$ a change in the patient role can also be seen in the context that people today are more educated and informed than has earlier been the case.

The paternalistic approach that has characterized the relationship between doctor and patient should be seen as obsolete. When several parties collaborate, it may be difficult to formulate one single objective, since each organization has its own goals. It is, however, important that all parties involved are aware of the overall purpose of the care actions concerning an individual patient and make sure that this is in accordance with their own and with the patient's goals. ${ }^{36}$

Peikes et $\mathrm{al}^{37}$ discuss a patient-centered medical home as a promising model that aims to reinvent primary care so that it is accessible, continuous, comprehensive, coordinated, and delivered in the context of family and community and, in so doing, aims to improve the outcomes of quality, cost, patient and family experience, as well as health care professional experience. Porzio et $\mathrm{al}^{38}$ discuss how a multidisciplinary and expert team, which is closely integrated with the hospital, can guarantee a long length of home care, avoiding hospitalization, and closing the gap between the patient's preferences and the services offered regarding the place of death. Collaboration needs to take place both at the top strategic and at the middle tactical management levels, as well as among the staff carrying out the care. ${ }^{39-42}$

\section{Gustav Samson scenario}

The fictitious patient Gustav Samson is in a palliative care situation with multiple diseases and receives care at home from several care units. The scenario has the function of placing the reader in a concrete care situation with the aim of creating a better understanding about the current care situation today. This patient scenario describes and clarifies a complex health and social care situation with many care problems with several individuals, care professions, care units, and organizations involved. It illustrates what the reality actually looks like over a few days' time for a patient in Gustav's situation.

Gustav Samson, the main character, is 72 years old. Gustav is in need of a substantial amount of different types of care treatments. Gustav is seriously ill and in a palliative stage.
He has a brain tumor with growing metastases. He is also diabetic and suffers from angina, high blood pressure, leg ulcers, and emphysema. Furthermore, he has suffered from depression with anxiety over the last 5 years. For these ailments, he receives medical palliative treatment, psychiatric support, and support from primary health care and social care units. There are a number of actors involved in Gustav's care.

Figure 1 shows the different types of care professionals, relatives, friends, and others involved in Gustav's care. It is quite possible that many of them are not aware of each other. They are normally not from the same care provider, and their work is not usually coordinated in a common care plan. ${ }^{43}$ Furthermore, all care providers have their own IT system, and these are usually not able to communicate with each other. This often leads to responsibility for Gustav's care falling between the cracks, so that he does not receive the health care and social care with the proper quality and proper patient safety that he needs.

Gustav lives alone in an apartment in Stockholm. He has been divorced for many years, and he has no children. Emma is Gustav's partner, and she supports and helps him in various ways. However, she cannot help him in his daily life since she works and lives in a place 300 kilometers from Stockholm. They usually meet on weekends. Gustav visits his family doctor regularly to follow-up on his diseases. For his medical and nursing needs, he has regular contact with Inger, his primary nurse, who visits him every week to administer his drugs.

For his psychiatric disorders, Gustav has help from the local psychiatric unit with some social care actions and support from a psychological support team. For assessment and treatment of his mental problems, he has contact with a psychiatrist, who follows-up his mental problems and

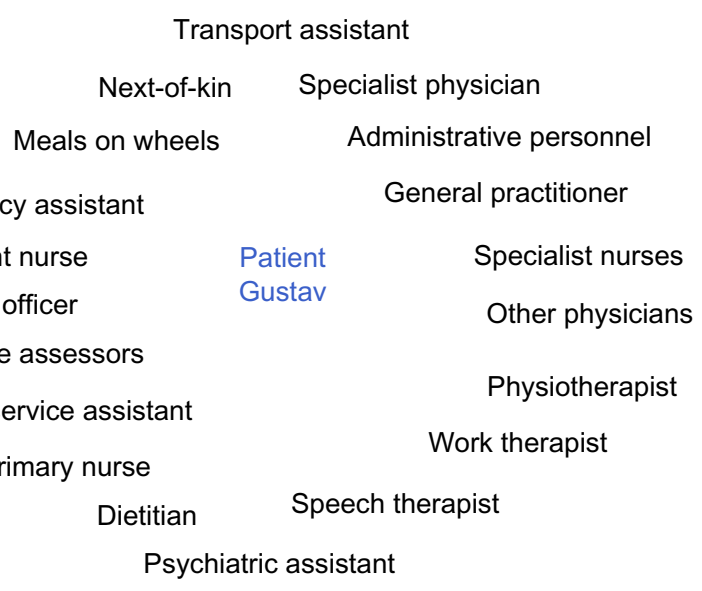

Figure I Many care professionals and field specialists provide care actions and support to Gustav at home. 
prescribes drugs and other treatment. Gustav has social care service to support him with a shower once a week and with cleaning the house and washing clothes three times per week. He has support with meals three times per day. He also has transportation service when he needs to visit the hospital.

\section{Health and social status for Gustav Samson}

In the last 3 months, Gustav has experienced spells of dizziness and has had bad falls several times at home. Four weeks ago, he was very ill with headaches, dizziness, and nausea, when the social care service unit visited him. Three weeks ago, Gustav was in contact with the primary nurse who, after an acute visit, considered that it was best to send Gustav to the emergency room (ER) at the hospital for assessment. After the first assessment at the ER, Gustav was sent to the neurosurgeon to undergo further clinical investigation. They established that he had an inoperable malignant brain tumor. His treatment of chemotherapy should be deployed immediately with a palliative purpose. Gustav was told that he would also receive chemotherapy for the tumor and the metastasis with a palliative purpose. Gustav listened to this information and got very anxious and worried. Gustav and the doctor also talked about palliative care at home and how it would be performed. They decided to organize a care-planning meeting with all involved care providers.

\section{Reading instructions for the scenario}

The heading "Fact" describes the regulation, legal, and economic situation. "Types of time" designates each day of the event description. Time is expressed in minutes. The text describes the estimated time consumed for the task split up in types. Time is described in various types, such as:

- Working time - time that is actually spent with the patient;

- Travel time - traveling to and from the location of care and travel to retrieve material associated with the treatment of the patient;

- Coordination time - time needed to coordinate actions with other health and social care providers;

- Wasted time - time wasted with unnecessary hassle, to sort out misunderstandings, duplicate work, missing actions, etc, arising from lack of information and/or lack of coordination of information.

The "Problems" section highlights the problems, risks, etc, from a patient, from relatives, and from organizational perspectives.

\section{3 days in Gustav's life}

The scenario describes the course of events during three days in Gustav Samson's life. The background is that, in the careplanning meeting, Gustav, his partner Emma, the responsible nurse, and the assistance assessors from the municipality participated and decided that Gustav should remain in the hospital for an additional 2 days. Due to this, Gustav needed increased help with his personal care, because he had greater difficulties to cope with in his daily hygiene. He also has difficulties walking by himself without assistance. A medical assessment stated that Gustav needed palliative care. A referral for this was sent to the unit for advanced medical care at home (ASiH). The assistance assessors contacted the social care unit as well as a night team unit (a commercial organization) to discuss Gustav's need for nursing. The nurse informed them that Gustav was prepared to go home and of the care he needed. The assistance assessors also sent a service order to the social care unit, assessing what to do and the appropriate time schedule.

\section{Fact}

When Gustav arrives at the hospital unit, the nurse sent a fax to the municipality administration to inform them that Gustav has been admitted to the hospital. When the investigation was completed 1 week later, the doctor found that the hospital could not do much more for Gustav. A request (with information to delegate responsibility) was sent to the municipality, which announced that Gustav was ready to leave the hospital and to go home. The grounds for this fax are the act (1990:1404) concerning local responsibility to pay for certain the National Board of Health and Welfare regulations (SOSFS 2005:27) on collaboration and care planning.

\section{Day I, at home}

Today, it is time for Gustav to go home from the hospital. He is nervous and worried about it. Emma arrives at the hospital to accompany him home in a taxi. Emma calls the social care unit to ask them to visit Gustav during the evening, since she is traveling back to Delsbo. Gustav feels more peaceful and harmonious to be at home again. It has required much coordination on Emma's part to make everything work. What would have happened if she had not taken hold of the coordination concerning all actions involving all parties, such as the hospital, the family physicians, and the social care unit? It is a huge responsibility to carry! Emma leaves Gustav at $6 \mathrm{pm}$ to drive back to Delsbo to work the following day.

Gustav's thoughts: "Oh, finally, I can sleep in my own bed. It was nice that Emma stayed with me yesterday at 
the hospital. I wonder who will come to assist me tonight. I did not understand what they were talking about at the hospital. I hope Emma knew and understood what they were saying."

The breakdown for the time for completion of care is: relatives, Emma; working time, 90 minutes; and coordination time, 60 minutes.

\section{Fact}

A decision on the need for social care has been taken by the assistance assessors, according to the Social Services Act (SOL). The decision is based on Gustav's situation and his needs for the moment. The assistance assessors send a requisition to the municipality social care unit in the area where Gustav lives.

\section{Problems}

At the hospital, the patients receive too much information, which they find difficult to remember.

$6.30 \mathrm{pm}$ : The doorbell rings. Gustav's thoughts: "I will try to go to open the door. But, oh, how difficult it is to get up from my chair, and where is my walker now?" Gustav hears a key inserted into the lock. Someone comes in, shouting, "Hey, it is Nils."

\section{Problems}

The patient is unaware of the care plan. Nils helps Gustav to wash and to get undressed. He changes the sheets on the bed and arranges with some other small things. Nils also brought this week's dinner menu from the social care unit. Gustav has to cross what he wants to eat during the week.

Gustav's thoughts: "Oh, it is difficult to choose food for every day of the week."

The breakdown for the time for completion of care is: social care unit, Nils; working time, 40; travel time, 20; and coordination time, 20.

\section{Day 2}

9 am: Sara comes to visit Gustav, according to the care plan. Sara is Gustav's assistant in the social care unit. She helps him with breakfast, and they are sitting down to make an activity plan for Gustav. The activity plan includes the need for help and support in his social life.

The breakdown for the time for completion of care is: social care unit, Sara; working time, 30; travel time, 20; and coordination time, 30 .

10.30 am: Gustav's thoughts: “... I am tired. Now it is nice to be alone and to have a short rest. Wonder what is for lunch?" The doorbell rings again, and Gustav tries to get out of bed and grasp the walker. It will take some time for him to open the door. Gustav's thoughts: "Who is it? Has Sara forgotten something? Why does she ring the bell? She has a key!"

Outside the door, primary nurse Inger is waiting. She is going to distribute the prescription drugs in a medicine box. Together with Gustav, she will go through the new medicines that the hospital has prescribed. She tells Gustav that she will delegate a person from the social team to give him the medicine from the medicine box. She discusses with Gustav about the new situation that has arisen, how he feels, and the status with his diabetes.

Gustav's thoughts: "Oohh, that is a lot to remember! She talks very much. I just want to be alone now. I hope that she will go soon. It is good that they come, but there are so many people coming, and it is a lot of information to keep track of."

The breakdown for the time for completion of care is: primary nurse, Inger; working time, 40; travel time, 20; and coordination time, 60 .

\section{Fact}

The general practitioner's clinic contacted the municipality via fax. The information states that Gustav needs palliative care at home and that a referral is sent to ASiH. The primary nurse leaves the responsibility to a person with less education to perform care action, delegating responsibility to some at the municipality's social home care staff to distribute medicine to Gustav from the medical box. At the care-planning conference, it was decided that $\mathrm{ASiH}$ should take the medical responsibility for Gustav. The health care center will therefore be disconnected. ASiH also takes responsibility for Gustav's other diseases, such as diabetes, angina, and emphysema, indicating that $\mathrm{ASiH}$ will take full medical responsibility for Gustav concerning the medical procedures at home. This means a smaller contact area for him than concerning the medical treatment.

$12 \mathrm{pm}$ : The doorbell rings. Gustav wakes up after a short sleep. Gustav's thoughts: "It is more stressful to be at home than I thought. At the hospital, everything that I needed was so close, and I was just to ring the bell when I needed anything. What was that noise?"

It was Sara with the lunchbox. She prepares the food and searches for the medical box to give him the medicine.

Gustav's thoughts: "It is probably best I get up and eat, but I am feeling a little giddy."

Sara comes to the bedroom to help Gustav to the lunch table. He needs her arm for support to get up. He takes the 
walker and goes to the kitchen. Sara walks away and says that it will be Annelie who will come and look after him in the afternoon and that Nils will come in the evening.

Gustav's thoughts: "I wonder what they will look for." Gustav goes to have a rest after his lunch.

The breakdown for the time for completion of care is: social care unit, Sara; working time, 15; and travel time, 20.

3 pm: Gustav wakes up and feels that he had a really good sleep. "It was good to rest in peace for a while. Now it would be good with a cup of coffee. I will try to go to the kitchen and make it."

$3.15 \mathrm{pm}$ : The doorbell rings, and a key is inserted into the lock. Someone calls from the hallway, saying, "Hey, hey, this is Annelie."

"Oh, I would love to have a cup of coffee! It would be really good right now."

Annelie helps him to make the coffee, and then she clears the table. She asks how Gustav is doing, and if there is anything else with which he needs help. He cannot think of anything else, so Annelie cleans up after lunch. They talk for a moment about Gustav's hospital stay and what has happened in the recent days.

The breakdown for the time for completion of care is: social care unit, Annelie; working time, 30; and travel time, 20.

$5.30 \mathrm{pm}$ : The doorbell rings, and a key is inserted into the door together with a bang. The social care unit comes to make a light dinner for him. It is Abdou who works tonight, because John is sick.

Gustav's thought: "Abdou ... I have never met him before."

Abdou finds something in the freezer to warm up for Gustav. Gustav does not know what is in the freezer. It was Emma who did the shopping, and he could not remember what it was. Abdou cooks his dinner, sets the table, and then leaves Gustav.

Gustav's thoughts: "I wonder if there is anyone else coming tonight. I hope I can remove the bedspread on the bed by myself."

The breakdown for the time for completion of care is: social care unit, Abdou; working time, 20; and travel time, 20.

\section{Problems}

- There are too many people involved. Planning is not clear and consistent for the patient.

- Many health and social providers meet at the home of Gustav, and they are not aware of each other's roles and the planned actions.
$9 \mathrm{pm}$ : Gustav falls asleep in front of the TV. The doorbell rings. Gustav hears a key in the door, followed by a "Hello." Abdou comes in and says that it is time to go to bed.

"Who decided this, I wonder? But now, I am very tired, so it will be nice to go to bed. I wonder why I am so tired. I have not been like this before." Abdou helps Gustav to the bathroom, so he can brush his teeth and wash himself. Then, Abdou helps Gustav get undressed and go to bed.

The breakdown for the time for completion of care is: social care unit, Abdou; working time, 30; and travel time, 20.

4 am: Gustav sleeps restlessly during the night and is anxious. He is very worried and feels the pains in the chest maybe it is the angina again.

Gustav's thoughts: "What should I do? I will call Emma, so I can talk to her for awhile."

He calls Emma. She becomes worried that something might have happened. They talk, and she manages to calm him down after awhile. He falls asleep after taking a tablet of nitroglycerin for his angina and a sedative tablet he can use if necessary.

The breakdown for the time for completion of care is: relatives, Emma; working time, 30.

\section{Day 3}

$8 \mathrm{am}$ : The doorbell rings. Gustav, lying in bed, finds it difficult to get out of bed to go and open the door. It takes a very long time for him to walk to the door. After much trouble and uncertainty, he is totally exhausted as he opens the door. It is the primary nurse Gunnel, who comes to put a new dressing on his leg ulcer.

The breakdown for the time for completion of care is: primary nurse, Gunnel; working time, 30; and coordination time, 20.

\section{Fact}

Before Gustav's hospital stay, the primary nurse put a bandage on Gustav's old leg ulcers. She has assessed the need to change the dressing once a week.

8.30 am: Again, Gustav hears a key in the door and a different voice. Greta comes from the social services unit to assist with breakfast; she intends to help Gustav with a shower today since she has time.

Gustav's thoughts: "Well, this day sure started with full speed. New people all the time. I get very confused. Where does everybody come from, and what do they want to do?"

The primary nurse Gunnel says she will put a bandage on Gustav's leg ulcer and that it is not good to take a shower 
now. Gunnel demands that Gustav must have a shower another day. When Gunnel has finished the dressing work, she tells Greta that the bandage will stay on for a week. Gunnel says that she will contact the social care unit, to go through the planning and the information about the leg ulcer, and the other treatment that Gustav is receiving.

\section{Problems}

- Patient at risk for medical errors and preventable harm;

- Inadequate planning and coordination, and inefficient use of staff resources;

- Lack of quality of care.

Gunnel discusses the problem that it takes a long time for Gustav to open the door, and that it will be difficult for the social care unit to fit the exact times when the primary nurse will be there to put a bandage on the leg wound. Gustav becomes irritated and tells them to go away.

The breakdown for the time for completion of care is: social care unit, Greta; working time, 30; travel time, 20; coordination time, 30; and wasted time 30 . For primary nurse, Gunnel, the numbers were: working time, 30; coordination time, 20; and wasted time, 20.

\section{Problems}

- Patient feels unsafe at home;

- Lack of procedures for key management.

11 am: The doorbell rings. Gustav shouts out from the bedroom that the door is open, it is OK just to enter. In comes a taxi driver who is irritated because Gustav was not down at the entrance and waiting for the taxi.

Gustav's thoughts: "What is the matter now? What is he doing here?"

The driver says he comes from the transportation service and is going to drive him to the oncology clinic at the hospital.

Gustav's thoughts: “Oncologist ... what is that? What should I do there? Yes, there was some talk about treatment that I should attend. I better follow along."

The breakdown for the time for completion of care is: transportation services; working time, 60; travel time, 60; and wasted time, 10 .

\section{Problems}

- Relatives work as coordinators.

- Organizations have shortcomings in taking responsibilities for coordination of the patient's whole health care situation.

\section{Fact}

Gustav has - during the last year - been granted transport service. The assistance assessors from the municipality have assessed the application and submitted it into County Council transport service for the board's decision. The hospital has an appointment for him at the oncology clinic for chemotherapy treatment for a palliative purpose. The hospital ordered the transport service.

$12.15 \mathrm{pm}$ : The doorbell rings. He hears a key in the door and then, "Hello ... it is Sarah," she cries from the hall. She receives no answer, gets worried, and searches the apartment for Gustav. She notices that the apartment is empty. She puts the lunchbox in the fridge, leaves, and locks the door. She goes down to the social care unit to contact Greta, the person who visited Gustav in the morning, to ask if she knows where Gustav is. Greta is not there and cannot answer the phone. She even calls the primary nurse, who does not answer. Then, she calls Emma. Emma has a feeling that Gustav should be at a treatment at the hospital, but she is not sure what day the appointment is. Sara talks with the manager for the social care unit, and they decide to call around to try and find out where he is.

The breakdown for the time for completion of care is: social care unit, Sara; working time, 60; travel time, 20; wasted time, 60; coordination time, 60 . Also, the time breakdown for Emma was: working time, 60; wasted time, 60; and coordination time, 60 .

3 pm: Gustav is at the hospital's oncology clinic. Gustav feels unwell after his chemotherapy. He has nausea, a headache, and needs to stay overnight at the hospital. He calls Emma to say that he is still at the hospital.

$3.30 \mathrm{pm}$ : Emma calls the social care unit and tells them what happened. They decided that Emma should call when Gustav gets home again. Gustav is sleeping very badly during the night. He feels sick and is very worried and anxious. The doctor says he must go home in the afternoon. Gustav still feels sick, and he is feeling uncomfortable about going home. Emma talks to Gustav for a long time to try to calm him down.

$4 \mathrm{pm}$ : Emma calls the hospital to tell them that he is very nervous about going home. She tells them that she cannot be there the coming night. The treating physician decides to let him stay one more night.

The breakdown for the time for completion of care is: social care unit, Sara; working time, 30; travel time, 20; wasted time, 30; coordination time, 20. For Emma, the breakdown is: working time, 30 ; wasted time, 60 ; and coordination time, 60 . 


\section{Problems}

- Relatives often have the role as quality controller.

- This is a big responsibility and almost impossible since they do not generally have any medical knowledge, and they cannot possibly make a correct assessment of the patient's condition.

\section{Fact}

The assessment of Gustav's need for palliative care is complicated. A referral was sent to $\mathrm{ASiH}$ from the hospital. Gustav's prognosis does not look good, and it looks like he will deteriorate quickly. The ASiH doctor determines that Gustav will be enrolled in $\mathrm{ASiH}$ as soon as possible.

\section{Problems}

- Lack of collaboration between the hospital, primary care, and $\mathrm{ASiH}$;

- Creates anxiety for the patient because he does not know who will come and why.

\section{Fact}

In the care planning conference, it was decided that the municipality should take responsibility for the social care need (covered in the Act-SOL). The municipality's occupational therapist is responsible for individuals living at home. This is covered in the Act-HSL. The occupational therapist states that there are some necessary facilities required in Gustav's home. Gustav needs a walker, toilet elevation, handles to the toilet and the bed, lifting belt, and leg raiser to the bed and the armchair.

\section{Concluding remarks}

By means of a fictional scenario viewed from a patient's perspective, we illustrate the care situation for a patient with multiple illnesses. The scenario clearly points out a set of problems, needs and requirements when it comes to creating collaboration and coordination in a way that is safe and guarantees high quality care from a patient perspective.

We have followed Gustav during 3 days at home. It appears that Gustav did not receive the necessary care required. Many of the actors in health and social care do not know each other and are not even aware of the other provider's role. Their support efforts for Gustav as a patient are not being coordinated. This leads to wasted time for the care providers, and disturbance and frustration for Gustav. A great responsibility has been placed on Gustav's partner Emma to coordinate the care actions from the different providers. Coordination has been insufficient. Care staff resources have not been used in an optimal way.

Figure 2 depicts the many parallel, entangled processes from the scenario that need to be communicated and coordinated.

In the simultaneous care processes, described in Figure 2, there are care actors and stakeholders from different care units who need information about care goals, what is planned, what is performed and evaluated, and about other care actions in which the patient is involved. The patient's medical and health status should be described and understood as a whole and not only by each separate problem or diagnostic specialty, for example, femoral fracture, diabetes,

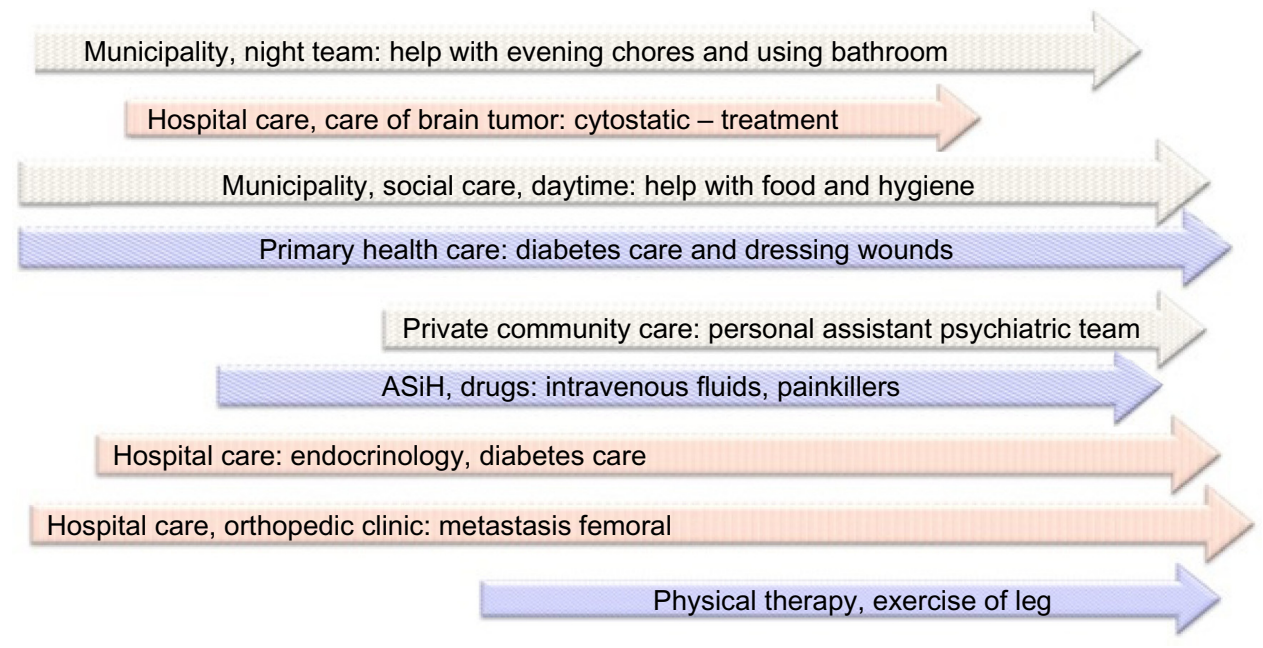

Figure 2 Examples of parallel and entangled processes that need to be coordinated between health and social care units. Abbreviation: $\mathrm{ASiH}$, advanced home health care. 
hypertension, and prostate cancer. Once the patient has obtained multiple diagnoses, new medical and nursing practices must be applied in a comprehensive way, addressing how to avoid negative aspects, such as side effects of drugs or other complications.

\section{Discussion}

Holistic care has become a vital component of health and social care reforms across Europe as the current situation of poor collaboration, coordination, and patient information sharing across both health and social care sectors results in substantial waste and inefficiency. ${ }^{26,27}$ The result from the scenario describes the requirements of coordination needed to obtain care quality, safe care, and value for the patient to establish clear care goals, to plan the care actions, and to follow-up the care results. There is a need for collaboration between care units and for a common patient-centered process that supports patient needs. The care organizations should be seen as a resource to perform the mutual goals in the patient's care plan. Today, most of the care processes are based on organizational goals of achieving economic efficiency for the individual care providers.

In the interviews, it was also stressed that wrong care decisions can be made and that time can be misused and wasted if no clear goals are set for the care of each patient.

In the following subsections, we discuss the main issues identified in the research projects. The issues presented were the ones mentioned in interviews and focus groups, as being the most important causes to the lack of collaboration between organizations and among individuals.

The issues are classified, according to the following categories:

\section{General}

1. Understanding what should be meant by a patient-centered collaborative care and the values behind it.

\section{Governance, leadership, and management}

2. Regulation such as laws, policies, and prescribed routines;

- Goals and objectives on a generic level;

- Reimbursement systems;

- Procurement of care.

\section{Operational level}

3. Collaboration/teamwork;

- Awareness of one's own role in the whole and the importance of communicating with others;
- Motivation and mandate, responsibility to communicate and to acquire knowledge of what others do;

- Coordination policy and tools;

- Proper communication tools and authority.

4. Conceptual structures and information.

Item 4 points to the need for information for all involved caregivers. Figure 3 provides an overview of information needs for all stakeholders in the patient-centered process - the patients', relatives', the care personnel's, and management's information needs. The disclosed information needs are based on the requirements made by the care staff and managers participating in focus groups and interview studies.

When collaboration does not work, for example, in a home care situation, palliative patients and multiple illness patients are often unnecessarily sent to the hospital - where they end up in the ER. This puts a lot of pressure and unnecessary costs on the county and also on other actors in the care of the elderly person. The elderly patient should instead be taken care of at home by a competent care team.

In the future, an overall goal ought to be to address the question of how to take care of the frail elderly and elderly with multiple diseases to minimize unnecessary contact with the ER, and - if possible - create a dignified care at home instead.

Two reports by the Swedish Government ${ }^{44,45}$ emphasize the fundamental importance of influence by the elderly and their relatives in decisions concerning what support services are required, how they should be performed, when, and by whom. The inquiry's overall proposals and assessments are all aimed at increasing values and the quality of care for the elderly. Many of the respondents in the VVP study ${ }^{9}$ put a great responsibility on managers at the various levels in the affected organizations, and they state that leaders must take responsibility to correct the underlying causes when the collaboration does not work.

One of the respondents, a VVP respondent, (an assistance assessor's manager), said:

... We would need a common organization that takes responsibility for all health and social care on a strategic level. But there may be risks that most of the budget might go for costly emergency care and not so much to the elderly. We must have different entrances to specialist care and the everyday care ...

Improved collaboration is likely to lead to improved coordination, which - in turn - can result in reduced duplication and inconsistencies in health and social care. Other effects can be: better knowledge of what other units and care actors 


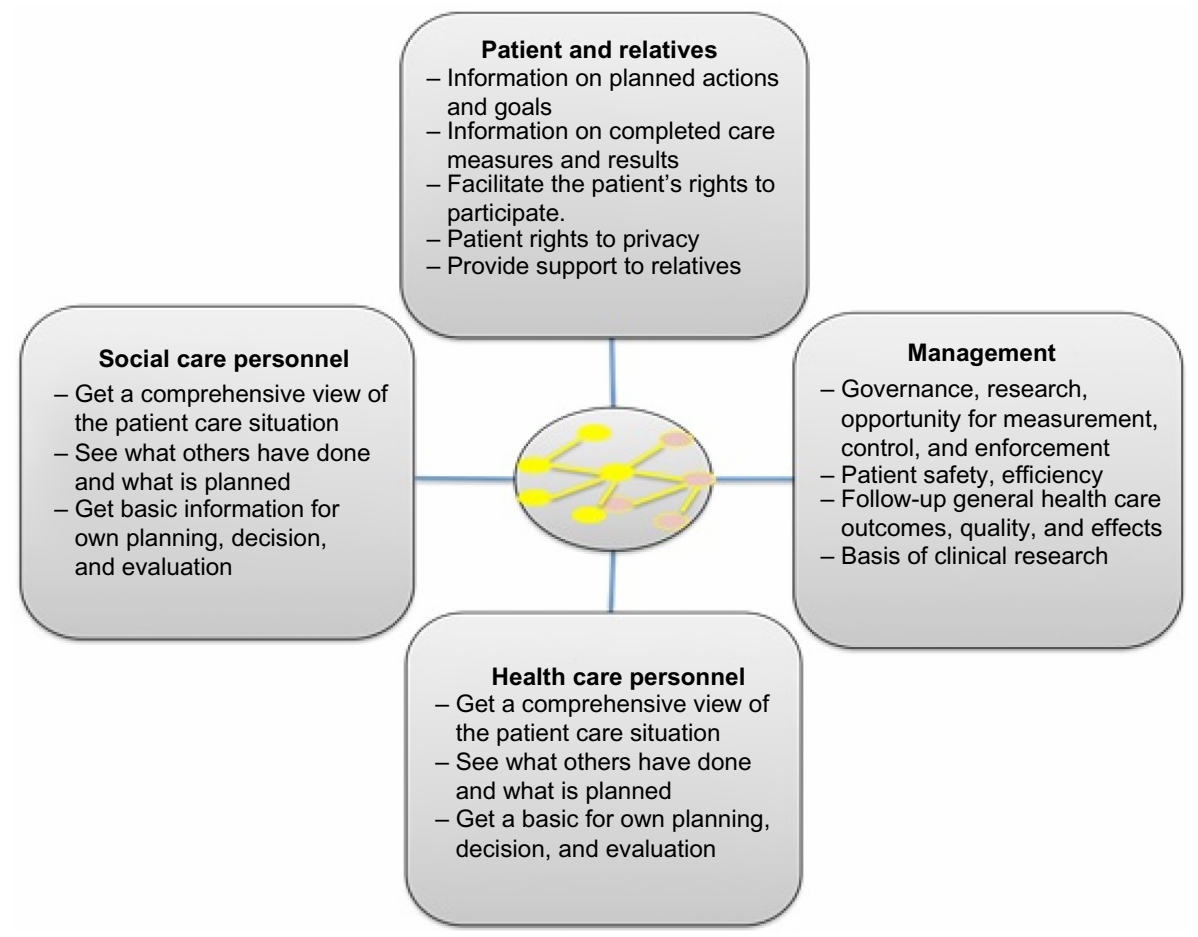

Figure 3 Examples of the different care stakeholders' need for information to perform patient-centered care.

are involved in; improved understanding of the patient's care goals; better understanding of the patient's overall goals; and common care planning. In time, there are probably opportunities to save resources and reduce costs through a more optimal use of existing resources, and by providing a sustainable and value-based care for the individual patient. This should result in better quality of life for the patient, with less suffering and more independent living. The model in Figure 4 defines causes, effects, and improvements of collaboration.

\section{Simple numerical example, based on Gustav scenario}

It seems from the scenario that there is a considerable savings potential if more efficient collaboration and coordination

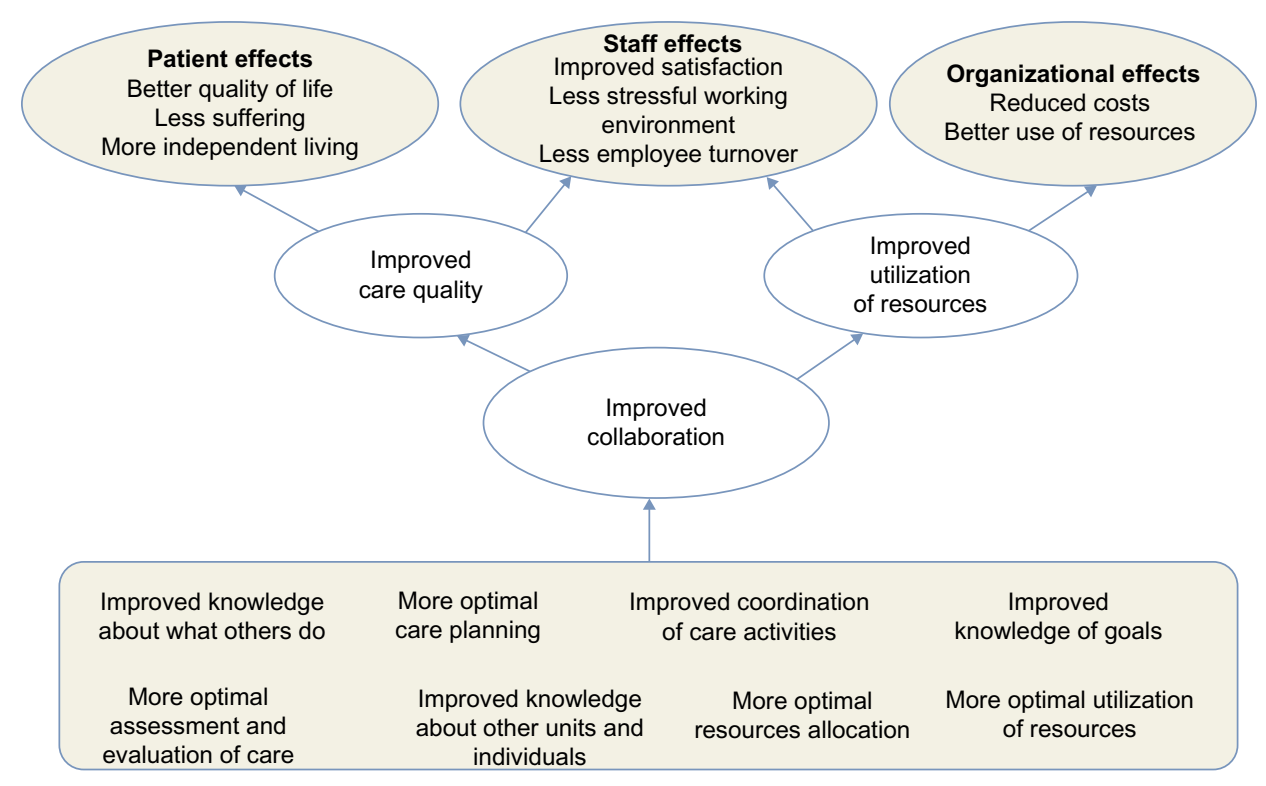

Figure 4 Causes and effects of an improved collaboration. 
were achieved. Therefore, a study of the savings potential was also carried out. The study estimated that the coordination time that could be saved was approximately 1 hour per day (MobiSams). We will use the coordination time as a numerical example on which to base calculations.

According to the interviews performed in March 2013 with procurement units at the Stockholm County Council and Municipalities in Stockholm, there were $\sim 4,000$ patients in a care situation similar to Gustav's. Since there is a great uncertainty in this number, 2,000 patients are used for the following calculation. Assuming that only 30 minutes instead of 1 hour per day could be saved with an average hourly cost of Euros (EUR) 71 per hour ( Swedish krona [SEK] 600 at the exchange rate SEK 8.5/EUR), a future coordination system could save around 247 EUR per week and patient. Even with the careful assumptions made, this would mean an annual EUR 26 million ( SEK 218 million) in savings for the Stockholm County Council and Municipalities.

The total population in the Stockholm region is $\sim 2$ million people. If the care situation in Stockholm is representative for all of Sweden, with close to 10 million citizens, then with the same careful assumptions as previously stated, the number of patients in care situations similar to Gustav's amount to $\sim 10,000$, and the potential savings on a national level of 30 minutes less per patient and day would amount to EUR 130 million ( SEK 1,200 million). Despite the advantages of adopting a coordination of all parties involved, these benefits are unevenly distributed among the various stakeholders. This means that some actors can get great benefits and carry only a small fraction of the total cost, while other stakeholders may bear a large part of total costs, but experience limited benefits. See the discussion in Juell-Skielse and Perjons. ${ }^{46}$

According to Porter, ${ }^{47}$ "health care is on a collision course with patient needs and economic reality." In today's dysfunctional health care competition, actors strive not to create value for patients but to capture more revenue, shift costs, and restrict services. Porter mentions that "the goal is value for patients" and that "improving value for patients is clearly the only valid goal for ethical reasons."

To overcome this obstacle, it is needed to ensure that local, regional, and national authorities are aware of the outcome of such a cost-benefit analysis and to understand the benefit for society at large to support such an investment. This requires new compensation systems and steering systems, providing stakeholders with drivers that support collaboration and coordination. Costs are likely to increase initially by the introduction, development, and acquisition of the new technology. The number of meetings will also increase by more comprehensive coordination, which also initially can lead to increased costs.

\section{Look into the future}

This section discusses the hypothetical future needs for collaborative information services to create a coordination of care around a patient with major health and social needs, with assistance provided by several care units. The purpose of this discussion is to provide a desired future image of what an improved health and social care might look like. This future story is based on the Gustav scenario and on knowledge generated from focus groups and interviews.

The patient and his/her relatives should also be actors in the care team, able to read and write their own parts of the records in a dialogue with physicians or nurses. New design of collaborative e-services can make it easier to plan and coordinate resources with the care actions that need to be performed. All interested parties, care professionals, patients, families, and leadership will be better aware of the other care stakeholders' responsibilities, care goals, actions, and plans. All the involved care providers act as a virtual team.

The collaborative and coordinated ICT support has also created better safety around the patient's care. It is possible by using e-services to evaluate care related to the patient's problem and to determine which individuals and organizations have been responsible for specific care actions, care plans, and care results. A patient such as Gustav has and will have multiple care plans from a number of goals, diagnoses, or problems, but - in this future discussion - they are integrated and coordinated. The planning of care actions has led to a safer and better care quality for the patient. In addition, medical injuries due to incorrect assessments and incorrect treatments can be expected to decrease. Stress among care staff is reduced when everybody knows what applies, who is responsible for doing what, when, and why.

Confusion and concern among family members and staff will - as a consequence - be reduced. The use of human care resources has become more effective and efficient. The care results are connected to the quality and impact of completed health and social care. Patients and relatives obtain a better understanding and participation in the care planning. They are informed about what will happen and what is planned for the patient.

The municipality, the county councils, and the private care providers have together developed a new strategy or a new care concept for collaboration and coordination. The new care strategy should result in providing good care for patients with multiple illnesses and for palliative patients, especially 
in the case of patients who require both hospital care and advanced home care. This new collaborative approach offers the individual patient a coherent health and social care that is optimized from the patient's perspective regardless of the organizations involved.

There would be an implemented common information structure that is based on a patient-centered care process with the needs of the patient as a starting point. The information structure is managed at the Swedish national level by an authority responsible for establishing and maintaining the model in a state that is feasible, generalized, and understandable. The ICT-industry is able to deliver e-services to a common open platform supporting collaboration. The possibilities of reaching goals to increase quality and patient safety would be significantly improved.

In summary, based on today's situation with many uncoordinated and costly care actions, there is probably a high potential to reduce the cost of the care of patients among the most ill elderly and patients with multiple illnesses. There are also estimated effects of preventable adverse drug reactions and of reduced medication errors. The suggested approach should also result in a better quality and more efficient care of the described patients. Waiting times, wasted times, and coordination times are expected to be significantly reduced, because of the more efficient use of existing resources.

To enable the effects of collaboration in and between care units, there is need of new mobile information service applications in the following categories:

- Coordinate care: coordination of assessment of care; planning of care actions and follow-up of improvement of care collaboration with other care units;

- Perform care actions: performing health and social care actions and presentation of the result;

- Resource allocation: allocating staff and other resources together with other care units, to reduce overall/total costs.

\section{Conclusion and further work}

There is, today, a lack of leadership and political mandate to maintain collaborative patient-centered care. The current situation and the challenges encountered worldwide include an aging generation with a longer average life expectancy, combined with a decrease in the overall birth rate. The proportion of elderly citizens with needs of care for multiple illnesses and for palliative care is expected to increase. We are living in a time when no care organization can succeed on its own. We are forced to move toward a more efficient use of available resources. A specific teamwork and coordination function or role needs to be defined that takes advantage of new types of information services as tools making it possible to plan and to coordinate care actions, care resources, and care results.

All the stakeholders involved need to have a reasonably common understanding of notions that have to do with teamwork and coordination of care actions (Figure 3 ). Information and process models defining how information should be understood and handled need to be developed and implemented. All stakeholders involved on a general level must agree on which information should be shared between care actors. There are needs for information about the patient and all care actions that he is involves in. New types of information services need to be developed to reinforce and facilitate care planning, performing care, and following-up care results. The information services should include support for rapid changes in the patient's common care plan and make it possible to take common responsibility in care actions.

To do that, we have to take on a whole new perspective, creating a new paradigm of how a future health and social care should be designed and developed. This will require a completely redesigned value-care strategy for the patient, of which the basis for building a care organization will probably not have the same structure that it has today.

Clear and common goals for how to create value for the patient need to be formulated. A common care process needs to be developed that - on a general level - describes the course of actions from a patient's perspective and that clarifies the role and responsibility of each organization and profession in that process. Clearer and more consistent regulation concerning collaboration and coordination needs to be designed. Awareness needs to be improved on all levels in the organizations about what collaborative care is and what effects it may have on the patients, on themselves, and on their organization in terms of quality of care, on patient security, on cost reduction, and on better coordination of care actions.

Strategies, policies and procedures should be described with the focus of solving the patient's problems and, where the care units are seen as the resource, to solve the patient's problem. Managers have to understand and agree on both the common responsibility and on how it relates to the responsibility of their own organization. To strive for a collaborative sustainable strategy (co-care concept) requires some steps to make collaboration work. An important aspect is that a strategy for collaboration must be long-term, be based on a holistic approach, be politically supported, and be accepted within and between organizations. 
The new strategy for collaboration may include the following major elements:

- New collaborative and coordinated way of working;

- Clear overall goals based on the patient's needs;

- Care result driven approach from a patient-centered perspective;

- Qualitative, patient-safe, and cost-effective collaborative and coordinated health and social care.

To successfully manage entangled and complex care processes in a very complex organizational structure that includes several principless represents a major challenge. ${ }^{42}$ The new patient-centered collaborative processes must be supported and accepted from the top political level down to the operational levels. Leaders and managers need to clarify to themselves and to others how the interorganizational care mission as a whole needs to work and how it involves themselves when it comes to understand the issues and takes responsibility as a leader to solve them.

Furthermore, responsibility has to be clearly distributed among all care staff involved so that everyone has a basic knowledge of who is doing what. The staff can be motivated through participation and by being involved in the planning of the patient-centered process. This would probably help the staff understand how their work contributes to improved collaboration and better results meeting the patient's needs, as well as obtaining a broader perspective.

Organizational responsibility has to be clarified, also concerning the managerial decisions. Requirements for collaboration and coordination must be taken into account during the procurement of care services. To achieve this, the care procurement units have to be trained in the new defined care models and how collaboration should work. This includes clear descriptions of what e-services are needed to support collaboration for all actors involved. Based on defined problems, there is a need to develop new collaborative e-services for patients with many diagnoses and with many care providers involved. The basis of the e-services should be an active, structured care plan as an instrument for planning, for coordination, for performance, and for following-up of the health and social care.

The next step should be to create a test bed for verification of patient benefits and values and to identify the bottlenecks for implementation of new ways of working, of innovations, and of e-services. Such a test bed should be located in a health and social care environment with good political and financial support of local municipalities and of county council in partnership with private care and in cooperation with research and industry. This test bed can also serve as a visualization environment to learn how future procurement can be done and what leadership, change management, and strategies for innovations in new collaborative patient-centered care concepts might look like.

Another conclusion is that - despite the fact that costs may initially be increased during the phases of development and implementation - it is possible to save a lot of resources with the proposal and that value may not necessarily be measured only in monetary terms but also in that it will be more patient safe and effective. Another advantage of the proposed solution could be that it decreases stress for all the actors included in the process.

One should also be aware that there might be limitations in that everyone who should be involved is not able or does not have an interest in creating a common care. Among other issues, there are legal and economic barriers to collaboration that must be solved in the long-term. Much remains to be done in making health and social care safer, more effective, more efficient, and more patient-coherent. It is our firm belief that each of the clusters of measures suggested in this paper will improve the state of health and care, and even more so when combined.

\section{Acknowledgments}

The authors wish to thank KK-Stiftelsen (Knowledge Foundation, Sweden) and VINNOVA (Swedish Governmental Agency for Innovation Systems) for funding the SAMS, MobiSams, and VVP project within which this work was done. Thanks also to all participants of the projects who took part in the project tasks of which this paper is a result. Special thanks to Professor Benkt Wangler and Professor Paul Johannesson both at Stockholm University, and to Richard Mattus, Gothenburg, Sweden.

\section{Disclosure}

The authors report no conflicts of interest in this work.

\section{References}

1. Statistics Sweden. The Future Population of Sweden 2009-2060. Stockholm, Sweden; 2009. Available from: http://www.scb.se/statistik/_ publikationer/BE0401_2009I60_BR_BE51BR0901ENG.pdf. Accessed March 20, 2014.

2. Teel AS. Alone and Invisible No More: How Grassroots Community Action and 21st Century Technologies Can Empower Elders to Stay in Their Homes and Lead Healthier, Happier Lives. White River Junction, VT, USA: Chelsea Green Publishing; 2011.

3. Wood DJ, Gray B. Toward a comprehensive theory of collaboration. J Appl Behav Sci. 1991;27(2):139-162.

4. Laurenson MC. Interprofessionalism in Health and Social Care: Working Towards an Inclusive Framework [doctoral thesis]. Huddersfield, UK: University of Huddersfield; 2007. 
5. Laurenson $\mathrm{M}$, Heath $\mathrm{T}$, Gribbin $\mathrm{S}$. Intervention in health care teams and working relationships. J Healthc Leadersh. 2012;4:117-126.

6. Hughes SL, Weaver FM, Giobbie-Hurder A, Department of Veterans Affairs Cooperative Study Group on Home-Based Primary Care. Effectiveness of team-managed home-based primary care: a randomized multicenter trial. JAMA. 2000;284(22):2877-2885.

7. Eng A, et al. Sams-project Final Report; 2005. Available from: http:// winge.blogs.dsv.su.se/files/2014/01/Sams-Final-Report.pdf. Accessed March 15, 2014.

8. Fors U, Gustafsson M, Johansson LÅ, et al. Slutrapport MobiSamsprojektet: Mobilt IT-stöd för samverkan i hemsjukvård. Available from: http://winge.blogs.dsv.su.se/files/2014/05/Mobisams-slutrapport-200702-21-kopia.pdf. Accessed March 18, 2014.

9. Andreasson S, Essler U, Fors U, Johansson LA, Strindhall M, Winge M. VVP-Värdeskapande Vårdprocesser Project, Innovativa processer for hållbar vård och omsorg Karolinska Institutet/Vinnova; 2009. Available from: http://winge.blogs.dsv.su.se/files/2014/05/ Slutrapport_VVP_Final.pdf. Accessed March 18, 2014.

10. Descombe, M. The Good Research Guide: For Small-Scale Social Research Projects. 4th ed. Berkshire, UK: Open University Press; 2010.

11. Johannesson P, Perjons E. A Design Science Primer. North Charleston, SC, USA: CreateSpace Independent Publishing Platform; 2012.

12. Koch S, Furubacke L, Edenius M, Erlandson BE, Rynning E, Winge M. IKT rapporten; 2008. Available from: http://www.ehealth. uu.se/IKTslutrapport.pdf. Accessed March 13, 2014.

13. Gustav Scenario produced in 3D video film. Available at: http://www8. informatik.umu.se/ eva/GustavSamson/Gustav3FlashMovie.swf and http://www8.informatik.umu.se/ eva/GustavSamson/Gustavdemo.swf.

14. United Nations Department of Economic and Social Affairs [homepage on the Internet]. World population to exceed 10 billion. United Nations Department of Economic and Social Affairs; 2011. Available from: http://www.un.org/en/development/desa/news/population/populationexceed-10-billion.html. Accessed March 19, 2014.

15. World Health Organization [homepage on the Internet]. Are you ready? What you need to know about ageing. World Health Organization; 2012. Available from: http://www.who.int/world-health-day/2012/toolkit/ background/en/. Accessed March 18, 2014.

16. Bodenheimer T, Chen E, Bennett HD. Confronting the growing burden of chronic disease: can the US health care workforce do the job? Health Aff (Millwood). 2009;28(1):64-74.

17. Vogeli C, Shields AE, Lee TA, et al. Multiple chronic conditions: prevalence, health consequences, and implications for quality, care management, and costs. J Gen Intern Med. 2007; 22(Suppl 3):391-395.

18. Bodenheimer $\mathrm{T}$. Coordinating care - a perilous journey through the health care system. $N$ Engl J Med. 2008;358(10):1064-1071.

19. Reid RJ, Wagner EH. Strengthening primary care with better transfer of information. CMAJ. 2008;179(10):987-988.

20. Smith PC, Araya-Guerra R, Bublitz C, et al. Missing clinical information during primary care visits. JAMA. 2005;293(5): 565-571.

21. Cameron A, Lart R, Bostock L, Coomber C. Factors that promote and hinder joint and integrated working between health and social care services: a review of research literature. Health Soc Care Community. 2014;22(3):225-233.

22. Rigby M. Integrating health and social care informatics to enable holistic health care. Stud Health Technol Inform. 2012;177:41-51.

23. Levine C. Rough Crossings: Family Caregivers' Odysseys through the Health Care System. New York: United Hospital Fund of New York; 1998.

24. Benyoucef M, Kuziemsky C, Rad Afrasiabi A, Elsabbahi A. Modeling healthcare processes as service orchestrations and choreographies. Business Process Management Journal. 2011;17(4):568-597.

25. Niehaves B, Plattfaut R. Collaborative business process management: status quo and quo vadis. Business Process Management Journal. 2011;17(3):384-402.
26. Poulymenopoulou M, Malamateniou F, Vassilacopoulos G. (2011). Specifying process requirements for holistic care. Inform Health Soc Care. 2013;38(38):302-312.

27. van Eyk H, Baum F. Learning about interagency collaboration: trialling collaborative projects between hospitals and community health services. Health Soc Care Community. 2002;10(4):262-269.

28. Malone TW, Crowston K. The interdisciplinary study of coordination. ACM Computing Surveys. 1994;26(1):87-119.

29. Hudson B. Joint commissioning across the primary health care-social care boundary: can it work? Health Soc Care Community. 1999;7(5): $358-366$.

30. El Ansari W, Phillips CJ, Zwi AB. Public health nurses' perspectives on collaborative partnerships in South Africa. Public Health Nurs. 2004;21(3):277-286.

31. El Ansari W, Phillips CJ, Hammick M. Collaboration and partnerships: developing the evidence base. Health Soc Care Community. 2001;9(4): 215-227.

32. Lichtenstein R, Alexander JA, McCarthy JF, Wells R. Status differences in cross-functional teams: effects on individual member participation, job satisfaction, and intent to quit. $J$ Health Soc Behav. 2004;45(3):322-335.

33. Ammenwerth E, Buchauer A, Bludau HB, Haux R. Mobile information and communication tools in the hospital. Int J Med Inform. 2000;57(1): $21-40$.

34. Pascoe J. Adding Generic Contextual Capabilities to Wearable Computers: Digest of Papers, Second International Symposium on Wearable Computers Second International Symposium on Wearable Computers, Pittsburgh, PA, USA, 19-20 October 1998. Piscataway, NJ, USA: Institute of Electrical and Electronics Engineers; 1998.

35. Eng A, Torpe T. Mitt Hälsokonto: Förstudie. Vinnova. Available from: http://www.vinnova.se/PageFiles/181503630/MHK1.pdf. 2008. Accessed March 19, 2014.

36. Aoun SM, O'Connor M, Breen LJ, Deas K, Skett K. Testing models of care for terminally ill people who live alone at home: is a randomised controlled trial the best approach? Health Soc Care Community. 2013;21(2):181-190.

37. Peikes D, Zutshi A, Genevro JL, Parchman ML, Meyers DS. Early evaluations of the medical home: building on a promising start. Am J Manag Care. 2012;18(2):105-106.

38. Porzio G, Aielli F, Verna L, Martella F, Aloisi P, Ficorella C. Integrating oncology and palliative home care in Italy: the experience of the "L'Aquila per la Vita" Home Care Unit. Tumori. 2013;99(2): $225-228$.

39. Winge M, Johansson LA, Nyström M, Lindh-Waterworth E, Wangler B. Need for a new care model - getting to grips with collaborative home care. Stud Health Technol Inform. 2010;160(Pt 1): $8-12$.

40. Winge M, Johannesson P, Perjons E, Wangler B. Managing the process conglomeration in health and social care, In Proceedings of 6th International Conference on Health Informatics - HEALTHINF 2013 , Barcelona, Spain.

41. Winge M, Wangler B, Johansson LA, Nystrom M, Lindh-Waterworth E. CO-CARE Collaborative Health and Social Care: Proceedings of 13th International Symposium on Health Information Management Research, October 2008. Auckland, New Zealand; 2008.

42. Winge M, Wangler B. Needs, Requirements, and e-Services for Collaborative and Patient-Centered Care. Aachen, Germany: Technical University of Aachen; 2013. Available from: http://ceur-ws.org/Vol963/. Accessed September 5, 2014.

43. Ring RM. Rapport: Vårdplanering - Det goda mötet? Work report from Dalarnas Forskningsråd.

44. SOU 2008:51, Statens offentliga utredningar (SOU), Socialdepartementet - Värdighetsutredningen. Available from: http://www.regeringen.se/ $\mathrm{sb} / \mathrm{d} / 108 / \mathrm{a} / 106288$. Accessed September 5, 2014.

45. Socialdepartementet, Sammanhållen vård och omsorg om de mest sjuka äldre; 2013. Available from: http://www.socialstyrelsen.se/ publikationer2012/2012-11-16. Accessed September 6, 2014 
46. Juell-Skielse G, Perjons E. New Challenges for e-government: Value Realization among Independent Actors: Fourth International Conference on Research Challenges in Information Science, Nice, France, 19-21 May 2010. Piscataway, NJ, USA: Institute of Electrical and Electronics Engineers; 2010.
47. Porter ME. Competitive Advantage. Available at: http://www.hbs.edu/ rhc/health.html. Accessed April 19, 2014.

Journal of Healthcare Leadership

Dovepress

\section{Publish your work in this journal}

The Journal of Healthcare Leadership is an international, peer-reviewed, open access journal focusing on leadership for the health profession. The journal is committed to the rapid publication of research focusing on but not limited to: Healthcare policy and law; Theoretical and practical aspects healthcare delivery; Interactions between healthcare and society and evidence-based practices; management; Research and opinion for health leadership; Leadership assessment. The manuscript management system is completely online and includes a very quick and fair peer-review system. Visit http://www.dovepress.com/ testimonials.php to read real quotes from published authors.

Submit your manuscript here: http://www.dovepress.com/journal-of-healthcare-leadership-journal 